Please quote as: Dünnebeil, S.; Sunyaev, A.; Blohm, I.; Leimeister, J. M. \& Krcmar, H. (2012): Determinants of physicians' technology acceptance for e-health in ambulatory care. In: International Journal of Medical Informatics, Ausgabe/Number: 81, Erscheinungsjahr/Year: 2012. Seiten/Pages: 746-760. 
Provided for non-commercial research and education use. Not for reproduction, distribution or commercial use.

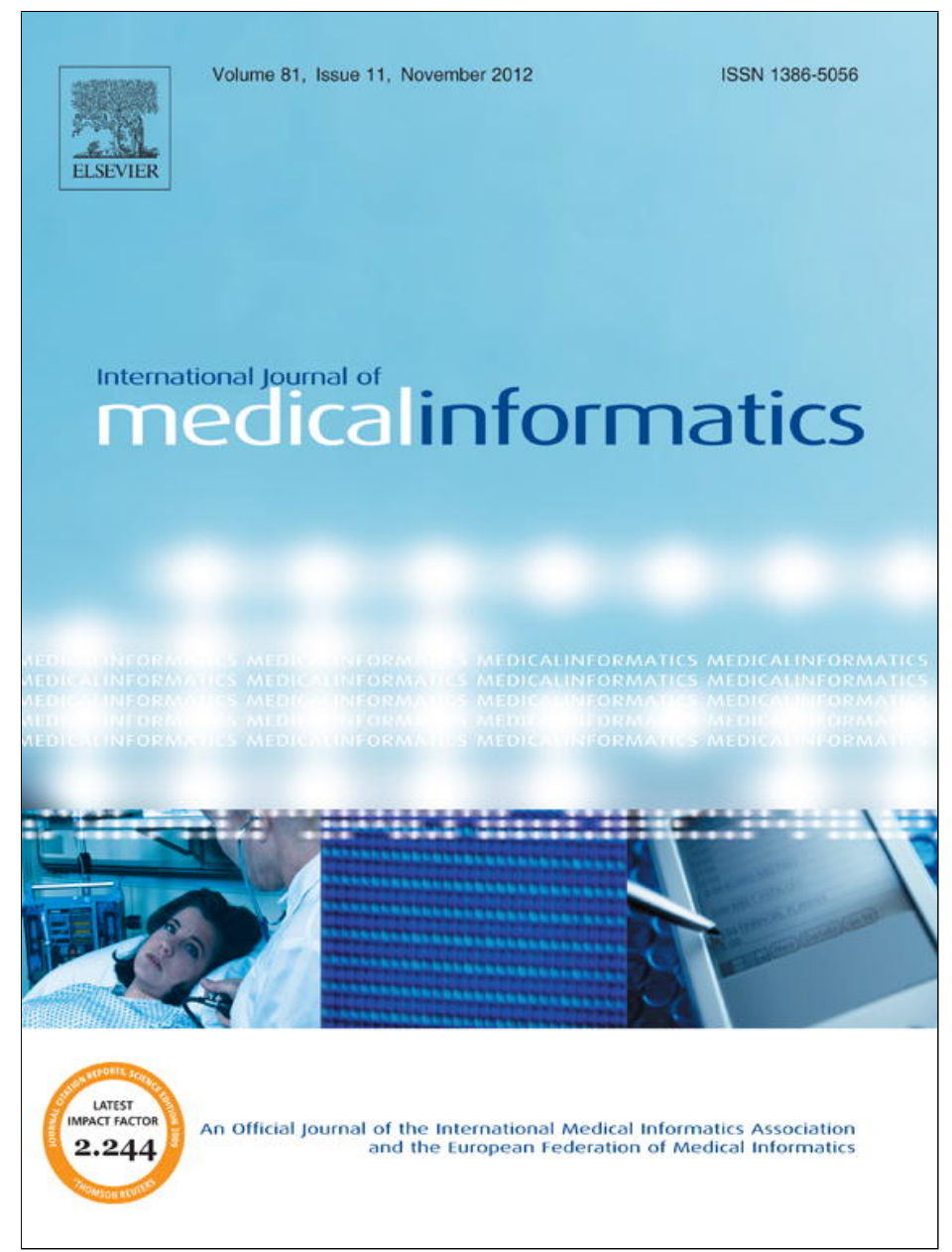

This article appeared in a journal published by Elsevier. The attached copy is furnished to the author for internal non-commercial research and education use, including for instruction at the authors institution and sharing with colleagues.

Other uses, including reproduction and distribution, or selling or licensing copies, or posting to personal, institutional or third party websites are prohibited.

In most cases authors are permitted to post their version of the article (e.g. in Word or Tex form) to their personal website or institutional repository. Authors requiring further information regarding Elsevier's archiving and manuscript policies are encouraged to visit:

http://www.elsevier.com/copyright 


\title{
Determinants of physicians' technology acceptance for e-health in ambulatory care
}

\author{
Sebastian Dünnebeil ${ }^{a}$, Ali Sunyaev ${ }^{b, *}$, Ivo Blohm $^{a}$, Jan Marco Leimeister ${ }^{c}$, \\ Helmut Krcmar ${ }^{a}$ \\ a Department of Informatics, Technical University of Munich, Bolzmannstrasse 3, 85748 Garching bei München, Germany \\ ${ }^{b}$ Faculty of Management, Economics and Social Sciences, University of Cologne, Germany

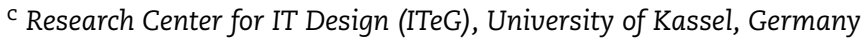

\section{A R T I C L E I N F O}

\section{Article history:}

Received 29 July 2011

Received in revised form

13 January 2012

Accepted 5 February 2012

\section{Keywords:}

Technology acceptance

TAM

e-Health

Ambulatory care

Telemedicine

Telematics

Germany

Determinants

Standardization

IT utilization

Process orientation

\begin{abstract}
A B S T R A C T
Background: Germany is introducing a nation-wide telemedicine infrastructure that enables electronic health services. The project is facing massive resistance from German physicians, which has led to a delay of more than five years. Little is known about the actual burdens and drivers for adoption of e-health innovations by physicians.

Objective: Based on a quantitative study of German physicians who participated in the national testbed for telemedicine, this article extends existing technology acceptance models (TAM) for electronic health (e-health) in ambulatory care settings and elaborates on determinants of importance to physicians in their decision to use e-health applications. Methods: This study explores the opinions, attitudes, and knowledge of physicians in ambulatory care to find drivers for technology acceptance in terms of information technology (IT) utilization, process and security orientation, standardization, communication, documentation and general working patterns. We identified variables within the TAM constructs used in e-health research that have the strongest evidence to determine the intention to use e-health applications.

Results: The partial least squares (PLS) regression model from data of 117 physicians showed that the perceived importance of standardization and the perceived importance of the current IT utilization $(p<0.01)$ were the most significant drivers for accepting electronic health services (EHS) in their practice. Significant influence $(p<0.05)$ was shown for the perceived importance of information security and process orientation as well as the documentation intensity and the e-health-related knowledge.

Conclusions: This study extends work gleaned from technology acceptance studies in healthcare by investigating factors which influence perceived usefulness and perceived ease of use of e-health services. Based on these empirical findings, we derive implications for the design and introduction of e-health services including suggestions for introducing the topic to physicians in ambulatory care and incentive structures for using e-health.
\end{abstract}

(c) 2012 Elsevier Ireland Ltd. All rights reserved.

\footnotetext{
* Corresponding author. Tel.: +49 221470 5397; fax: +49221470 5386.

E-mail address: sunyaev@wiso.uni-koeln.de (A. Sunyaev).
}

1386-5056/\$ - see front matter @ 2012 Elsevier Ireland Ltd. All rights reserved.

doi:10.1016/j.ijmedinf.2012.02.002 
1.

\section{Introduction}

Health information systems have the potential to significantly improve the quality of healthcare. Information technology (IT) in healthcare has been shown to reduce the incidence of adverse events, the administration of wrong medications, the number of hospitalizations and healthcare spending [1-6]. With this in mind, German health authorities are currently building a nation-wide telemedicine infrastructure (NTI) to enable innovations in the area of electronic healthcare (e-health) [7]. Even though most physicians in Germany acknowledge the potential advantages of e-health [8], the implementation of the NTI has been delayed for more than five years due to physician resistance [9].

Germany is not an isolated case: the low adoption of ehealth is a common pattern throughout the European Union [1] despite the huge potential of electronic health services (EHS). The utilization of electronic health records (EHR), a key e-health application, has not been uniformly adopted in medical practices and hospitals. Smaller ambulatory care practices rarely use advanced EHR systems [10]. There are examples of the use of IT in healthcare that seem promising but are not implemented because of resistance from key stakeholders [11].

The motivation to conduct this research was the resistance to accept and adopt national e-health projects in Germany. The NTI project, which provides a secure infrastructure for the diffusion of e-health, lacks broad support, especially among ambulatory care physicians. Several moratoriums filed by physician associations and politicians have caused changes in the specifications for e-health projects, leading to major downsizing of the projects [12]. The main reasons given for opposition to e-health are privacy concerns, the extensive efforts required to implement the project, and dissatisfaction with the performance of the technology $[13,14]$.

In order to analyze the acceptance of EHS and improve future adoption, it is necessary to first identify the issues that affect the intention to use e-health. Therefore, in line with research in technology acceptance [15], we investigated the factors that influence the intent to use, perceived usefulness (PU), and perceived ease of use (PEOU) of EHS applications by physicians in the ambulatory care setting. Data security is the main concern raised over EHS in Germany. We, therefore, included this topic in our research to investigate whether it directly impacts the intent to use or if it moderates either the performance or the effort expectation, or, more precisely, is it the major barrier in the adoption attitude. Attitude towards privacy can be positively altered with appropriate message framing [11]. The possible failure of the NTI project should be prevented as the NTI represents the opportunity to achieve secure and pervasive availability of EHS in the future. An extended technology acceptance model (TAM) could help to understand the mental model of physicians and reframe ehealth projects in an appropriate manner.

Our research targets the following two main research questions:

- Can existing healthcare-related TAM approaches be verified for e-health in the ambulatory care setting in Germany?
- What are the barriers and drivers for intention of use, PU, and PEOU for e-health applications in ambulatory care?

First, existing TAM approaches are verified in the given context. As several publications suggest, we develop the "left side of the model" [15] or the "barriers to technology acceptance" [16], and extend the established model with drivers and barriers which impact the intention to use EHS and test their actual impact. Currently existing TAM models do not consider barriers and drivers for adoption of technologies in e-health. We verify our proposed TAM model in the given context.

\subsection{Technological and socio-economical background}

There is no precise definition for e-health; it is widely used and has various characteristics according to the area of application. Oh et al. compared 51 definitions of e-health in 2005 [17]. For our study, we refer to a widely used definition by Eysenbach [18], which we consider suitable for the context of EHS in German ambulatory care:

"e-health is an emerging field in the intersection of medical informatics, public health and business, referring to health services and information delivered or enhanced through the Internet and related technologies [..]".

While we consider e-health as the broader term to reflect the application of health services for collaboration purposes, the services offered through NTI will subsequently be called EHS. Within the German NTI, it is planned to offer communication, cooperation, analysis and documentation features as web services to ensure pervasive availability and integrity of medical data to consumers in the public health system [2]. The major advantages resulting from the implementation of EHS are: (1) pharmaceutical drug safety, (2) insurance data maintenance, (3) electronic healthcare records (EHR), and (4) records of emergency treatment. The proposed infrastructure provides the storage of medical patient data on central servers or on smart cards, called electronic Health Cards (eHC) [19]. A major goal of the introduction of EHS is patient-centered medicine and the standardization, efficiency and transparency of medical treatment processes [20]. A commission composed of representatives from health insurance providers, medical associations, and governmental institutions worked out a proposal to guarantee universal accessibility of standardized data beyond institutional boundaries [21]. The proposal aims to ensure a reduction in healthcare costs by avoiding redundant examination of patients and administrative procedures and improving patient safety [7]. According to calculations, telemedicine services will provide added value of between 7.5 and 29.5 billion Euros by 2020 [22]. Fig. 1 illustrates the overall architecture of the German NTI.

Previously conducted surveys have shown that a large group of physicians has rejected telemedicine services that have been planned to be introduced as part of the implementation of the NTI $[8,13,14,23]$. Numerous campaigns have been started by medical associations and politicians in Germany calling for a moratorium on NTI initiatives [24]. These actions can be regarded as common reactions to the acceptance of telemedicine services by healthcare personnel [11]. Because of these problems in gaining acceptance by physicians, all 


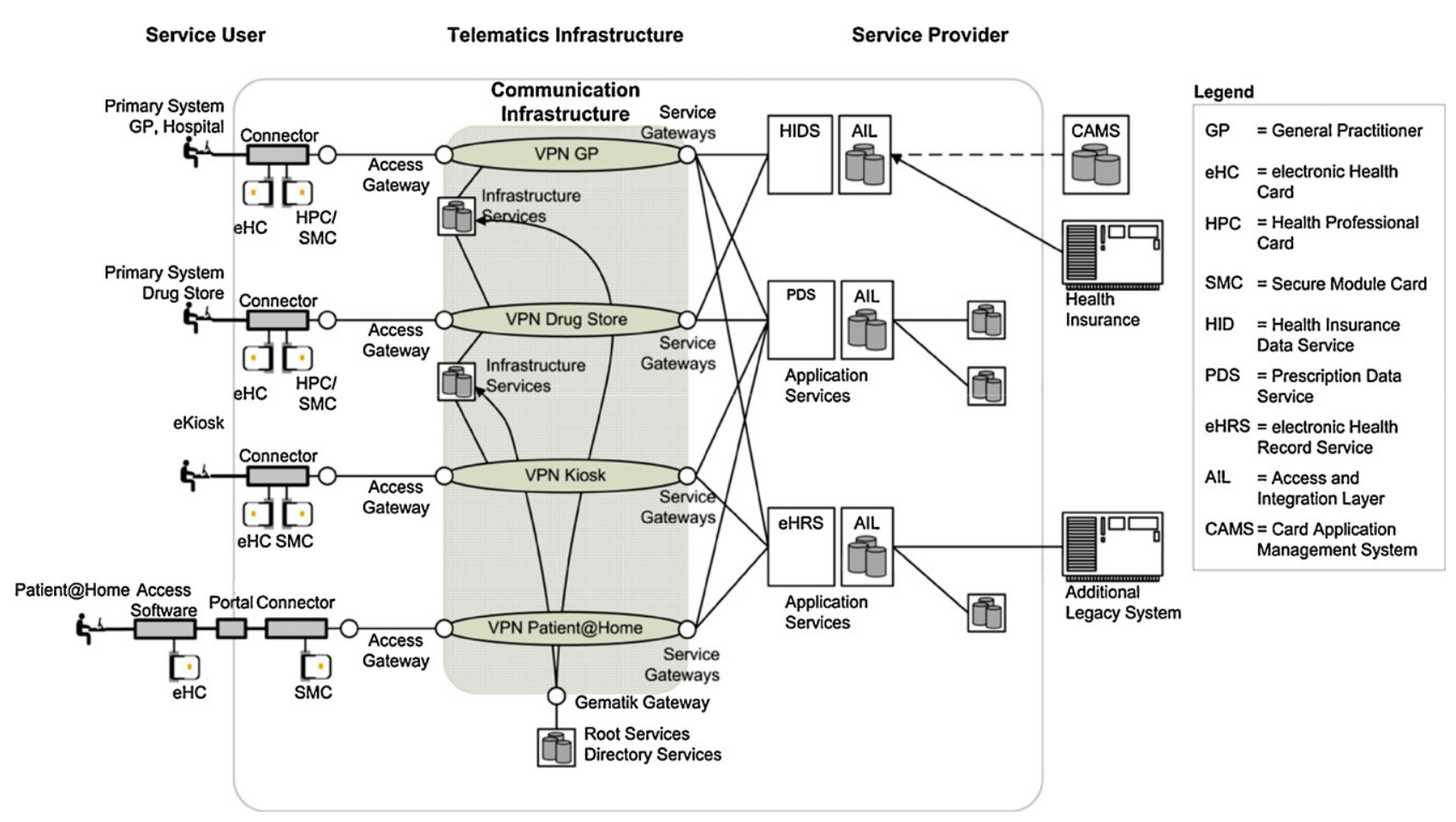

Fig. 1 - German National Telemedicine Infrastructure [19].

planned German NTI services, except the emergency record, have been indefinitely postponed. A nationally conducted study [22] concluded that savings achieved by the implementation of EHS might have had a negative financial impact on pharmacies, dentists, and physicians. While physicians could face a reduction in income, private and public health insurance companies would profit with savings of more than Euro 5 Billion.

\subsection{Technology acceptance in healthcare}

Technology acceptance describes an individual's intentional or voluntary adoption of a technology [25]. The rapid diffusion of IT in healthcare during recent years has led to intense involvement of physicians and patients with computer technology. User acceptance is an important factor for successful adoption and utilization of the targeted technology. During the last two decades, various models dealing with technology acceptance have been developed and verified. The effectiveness of several of these models were proven for a broad spectrum of IT systems, such as personal digital assistants or electronic medical records [26]. TAM is the most widely recognized model of behavioral intention of using information systems (IS) [27]. In the original TAM model, acceptance is explained by the influence of a person's attitude towards technology and the PU of the technology. The PEOU of the system positively influences the PU and the attitude towards technology. One of the extensions of TAM, the Unified Theory of Acceptance and Use of Technology (UTAUT) model by Venkatesh et al. [28], was successfully tested in the context of healthcare [29]. Holden and Karsh [15] and Yarbrough and Smith [16] have performed extensive reviews on previous applications of technology acceptance models (i.e., TAM and UTAUT) in healthcare. All quantitative studies reviewed in their articles confirmed that the behavioral intention of adoption of technology is significantly influenced by the PU of a technology. The PEOU also affects either the behavioral intention directly, via the attitude towards the technology or the PU. The UTAUT model appends the construct "social influence" to explain the behavioral intention to use a system. Fig. 2 summarizes the constructs of TAM and UTAUT and indicates significant relationships between the constructs.

We use the construct names from TAM as applicable to our study. We did not consider other models, such as the Extended Technology Acceptance Model (TAM2) [30] or theory of planned behavior [31], as they have not been applied in the context of healthcare. Key constructs of these models are included in TAM [25] and have been verified within the UTAUT model [28].

The utilization of e-health technology can either be enforced by health authorities or be achieved as a result of voluntarily adoption. In the German healthcare setting the electronic processing of treatment data (the management of patient data and the quality control of treatment) is not mandatory [3]. It is thus essential to convince physicians to voluntarily adopt the technology to obtain the medical and economic benefits of EHS. An earlier study in ambulatory care revealed that there are two groups of physicians: those with a high behavioral intention to use EHS and those who strongly reject the technology. There is no significant difference in behavioral intention by age or the field of specialization [23]. However, the utilization of advanced IT is especially low in small medical practices [10].

Our intention is to explore more factors that influence the attitude of physicians toward EHS. The main dependent variable in our research model is the behavioral intention to use 


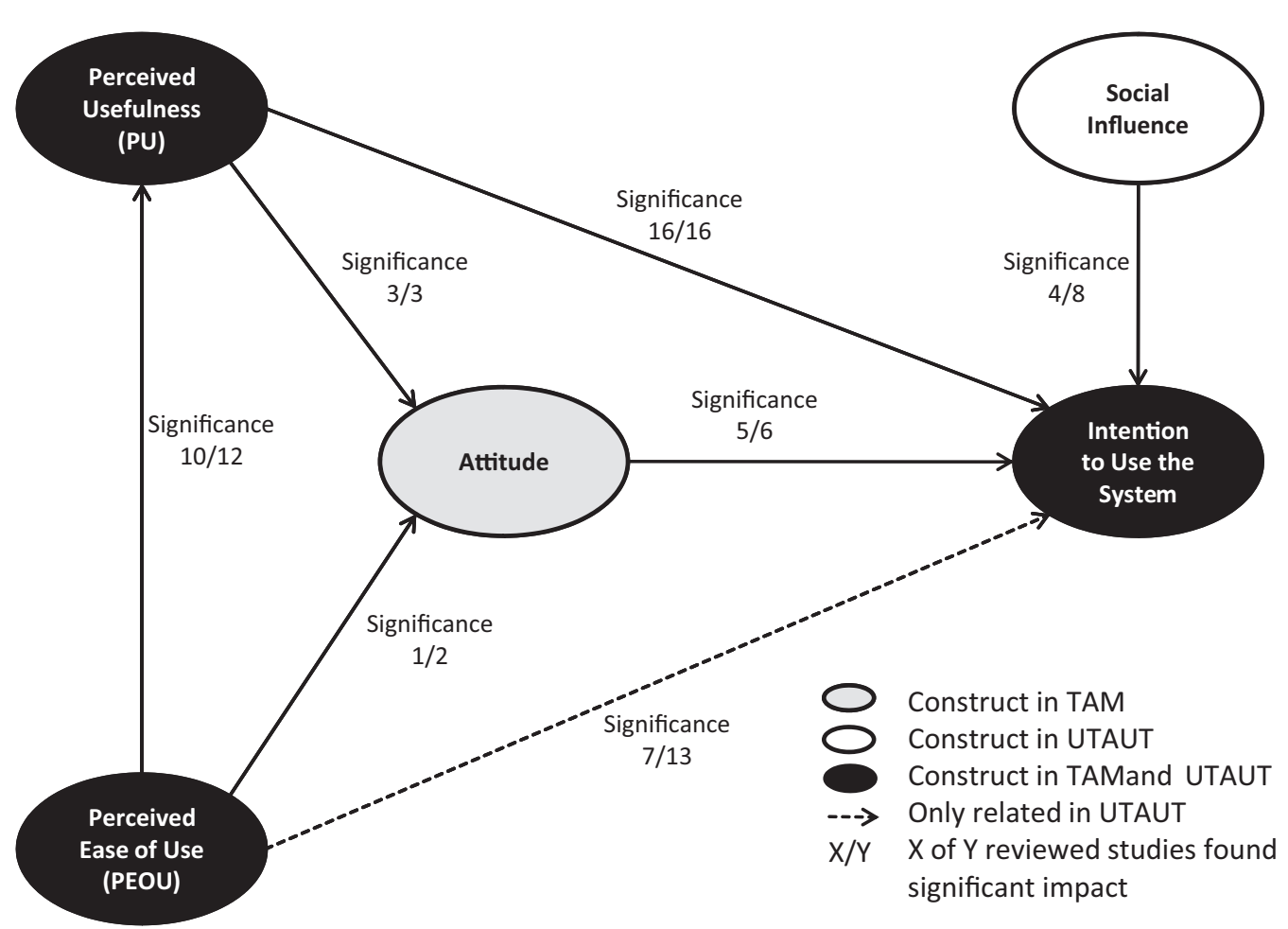

Fig. 2 - Count of significant relationships between TAM constructs as presented by Holden and Karsh [15].

EHS. The use intention can be considered as the acceptance of our target technology: e-health. As EHS are not yet been implemented in Germany, actual use could not be measured in this research. Apart from measuring the useage intention for EHS in general, we were keen to find out which factors affect PU and PEOU of e-health applications. Our study population was physicians in ambulatory care. This group cannot be considered to be homogeneous, as there is great variation in their daily routines. The number of patient treatments per day ranges from $<10$ to 120 . Some physicians have a "one-person" practice, while others are part of a group practice with up to 10 physicians. The importance of IT support might be lower in one-person practice due to the smaller volume of patients. In the following section we develop hypotheses on factors influencing the acceptance of technology. Using the wellestablished TAM constructs as a base; we add the perceived importance of various key e-health concepts to physicians.

\subsection{Model development for determinants influencing technology acceptance}

Using a review of empirical results of TAM in healthcare, we decided to operationalize the most commonly used constructs in healthcare-related TAM research. We chose PU, PEOU and behavioral intention as these factors had the highest support level in past TAM research in healthcare. To ensure the rigor of the research, we included constructs that were utilized in more than $50 \%$ of existing articles on TAM and that were found to be significant in more than $50 \%$ of cases. We did not use "Social Influence" and "Attitude" (compare Fig. 1) as they lacked support or relevance. The following sections explain the three hypotheses derived from TAM that we developed for this research. These hypotheses include the underlying drivers und obstacles for EHS adoption.

Ten of 12 studies on TAM research in healthcare found a significant positive influence of PEOU on the PU $[15,16]$. If systems are easy to use and suitable for integration into the daily routine, they are considered to deliver adequate performance in most cases. This finding is relevant because it points out that e-health applications can benefit medical professionals and patients. Broad adoption of e-health applications, however, has not yet occurred due to complicated handling issues and insufficient skill sets. Therefore, improving the usability of e-health systems is a key issue. We assumed:

H1. PEOU positively influences the PU of EHS.

PU has been defined as the degree to which users believe that using a system will help them to attain gains in job performance [28]. Previous research has employed constructs from different models, e.g., performance expectancy and PU [25]. The construct testing in UTAUT included aspects such as extrinsic motivation, job-fit, relative advantage and outcome expectations from older models [28]. The usefulness of IT system was found to be significant for user acceptance in all healthcare-related TAM studies $[15,16]$. Performance in ambulatory care can be described as higher patient throughput, better quality of treatment or the extension of medical services within an institution. Thus, we assumed:

H2. PU positively influences behavioral intention to use EHS.

According to Venkatesh et al. [28], PEOU is defined as the degree of ease associated with the use of the system. The 
constructs describe either the complexity or the usability of a system [25]. Physicians, who often have limited IT expertise, can be frustrated by the complexity and limited user friendliness of the software. In contrary, intuitive software design can directly influence the behavioral intention to use EHS. Thus, we assumed:

H3. PEOU positively influences the behavioral intention to use EHS.

\subsection{Extended model development}

In addition to the well-established constructs of technology acceptance, we derived six additional hypotheses from the literature and tested their influence on one previously chosen TAM construct.

Research by Sequist et al. [32] highlights how perceived advantages and disadvantages of EHR affect users' judgment of their IT experience. The perception of the current IT utilization does not only influence whether the use of EHS like EHRs are regarded as fulfilling, but also whether a person will even start to use EHS. Studies by Sequist et al. [32] and Mitchell [33] indicate that physicians' PU of EHS positively correlates with increased IT utilization. If a physician is already IT savvy, it is more likely that he or she will have a higher demand for EHS. This aspect is stated as being one of the basic principles of e-health usage [33]. It can be concluded that efficient IT utilization influences EHS usage behavior: the more online experience and IT utilization physicians have, the greater the PU of EHS. In accordance with this and other studies on the role of usage motives and their potential effects $[15,16,34]$, we focused on whether different motives for EHS use would influence physicians' decision to use EHS. Based on the studies conducted by Sequist et al. [32] and Boddy et al. [35], drivers behind EHS use we applied in our study were: (1) current use and perceived benefit of IT in medicine (defined by statements such as "I use the internet to keep up to date" and "I use emails to contact my patients"); (2) attitudes regarding the current use of IT (defined by statements such as "nowadays, it is unthinkable to work without IT" and "we use electronic medical records to deliver treatment results") and attitudes regarding the impact of IT on the quality of care, patient safety, patient-doctor interactions, rural and underserved healthcare; and (3) perception of delivery of culturally appropriate care (defined by statements such as "I believe patient health diaries are great for recording health problems" and "patients feel safe with our EHS"). These drivers of EHS suggest that high IT utilization positively affects the perceived importance of IT if IT is considered by the user to be dependable. We assumed:

H4. The perceived importance of IT utilization positively influences the PU of EHS.

The concerns regarding implementing NTI in Germany are the security and privacy aspects of the system. Physicians perceive data security as important as shown by the results of a survey of primary care clinicians involved in the implementation of an e-health application [32]. The prospective electronic data processing capability of the NTI can secure patient data in a manner that was impossible using the earlier paper-based documentation methods. Therefore, it is likely that greater perceived importance of data security positively influences the PU of EHS. According to Boddy et al. [35], trust in security and dependability of IT has a positive effect on perceived benefits of EHS. The advantages of EHS as addressed in this study are: access to a wide-range of physicians with different experiences in using e-health services (no experience, little experience and e-health service users); differing opinions by healthcare professionals on the security of patient data [35]; current use and perceived benefit of IT in medicine [32]; and attitudes regarding the implementation and current use of e-health services $[32,35,36]$. Disadvantages of e-health as addressed in this study are: passing of time while using e-health services; liability to document all patient-related activities; initial and ongoing financial investment in IT (IT costs); system availability, adoption, and deployment (IT infusion); clinical efficacy, efficiency, quality, and effectiveness (health performance); negatively perceived behavior of other stakeholders; and delayed feedback [36]. The fifth hypothesis addressed in this study is as follows:

H5. The perceived importance of data security in the provision of healthcare positively influences the PU of EHS.

Documentation of medical activities is one of the daily core duties of physicians and sophisticated documentation techniques require technical assistance. The performance and usefulness of EHS depends on the intensity and the elaborateness of documentation in medical practices. Leonard and Sittig [36] identified the widespread adoption of IT throughout the documentation process in healthcare provision. Gururajan [34] underlines the tremendous positive influence that IT has on documentation quality in healthcare. Proper documentation as well as computer accessibility and consistent implementation of protocols facilitate the successful implementation of practice guidelines in acute care settings [37]. Furthermore, perceived benefits of documented health services facilitate the improvement of healthcare quality [32]. Positive effects of well-structured e-health services (e.g., saving of time by physicians) are also noted [35]. According to Yasnoff et al. [38], physicians understand the importance of documentation in their practices and that standardized documentation is perceived to be an enhancer of EHS use. These studies suggest that EHS provides appropriate features to document the provision of healthcare. Thus, we assumed:

H6. The perceived importance of documentation in physicians' practices positively influences the PU of EHS.

The German NTI project faced significant resistance from healthcare professionals from the very beginning. Despite the resistance against the project itself, which resulted in two moratorium calls from the leading German medical association, several underlying e-health applications included in the NTI project are considered useful by the majority of physicians. Of interest, the group of physicians rejecting the project had a significantly lower level of e-health-related knowledge [23]. Furthermore, surveys have shown that only one-third of German physicians feel adequately informed about the NTI 
Table 1 - Research hypotheses.

\begin{tabular}{lll} 
Name & No. & \\
\hline Hypothesis 1 & H1 & PEOU positively influences the PU of EHS. \\
Hypothesis 2 & H2 & PU positively influences behavioral intention to use EHS. \\
Hypothesis 3 & H3 & PEOU positively influences the behavioral intention to use EHS. \\
Hypothesis 4 & H4 & The perceived importance of IT utilization positively influences the PU of EHS. \\
Hypothesis 5 & H5 & The perceived importance of data security in the provision of healthcare positively influences the PU of EHS. \\
Hypothesis 6 & H6 & The perceived importance of documentation in physicians' practices positively influences the PU of EHS. \\
Hypothesis 7 & H7 & Knowledge about e-health services improves the PEOU for EHS. \\
Hypothesis 8 & H8 & The level of standardization in healthcare practices increases the PEOU of EHS. \\
Hypothesis 9 & H9 & Process orientation positively influences the PEOU of EHS. \\
\hline
\end{tabular}

project [13]. At the same time, physicians consider themselves to be the key contact person for their patients concerning e-health application, and believe that they are responsible for properly informing their patients about available e-health applications [39]. Venkatesh states that in the absence of knowledge about the target system and limited direct behavioral experience with the system, individuals will base their PEOU of the target system on general, abstract criteria [40]. In the case of e-health applications, which are considered to be generally beneficial, better knowledge about the technology will result in higher PEOU because in most instances the details of the applications are judged rather than the entire project. Thus, we assumed:

H7. Knowledge about e-health services improves the PEOU for EHS.

Standardization in healthcare is a major effort in the medical as well as in the technical domain [41-43]. Technical standards exist for medical communication (Health Level 7 [HL7]) or Digital Imaging and Communications in Medicine (DICOM) which enable transmission of documents between various medical IS. The structure of medical documents can be unified, using semantic standards, such as Clinical Document Architecture (CDA), to create common document specifications which contain information on diagnosis, medication or treatment and ensure interoperability [44]. To ensure that the collaborating entities have the same understanding of a content item in a structured medical document, standardized medical terminologies are used. The International Statistical Classification of Diseases and Related Health Problems (ICD) assigns a unified coding to diagnosis thus ensuring a common understanding of medical contents. Treatment guidelines, developed by medical experts, aim to ensure a standard of treatment for specific disease entities based on the best medical evidence available $[45,46]$. Therefore, we assumed: the more a medical practice is (1) compliant with medical guidelines, (2) utilizes communication standards, (3) applies documentation standards, and (4) uses common medical terminologies, the lower the effort will be to adopt EHS. Standardized e-health software will likely include standardized guidelines for medical treatment and communication, as it is not possible to develop software adapted for individual medical practices. Thus, we assumed:

H8. The level of standardization in healthcare practices increases the PEOU of EHS.
Collaboration between facilities or institutions providing healthcare is essential for successful treatment, especially for chronic diseases [47]. According to evidence-based medical guidelines, patients pass through several treatment steps, representing a defined medical process, to ensure that they receive the best available medical treatment for their diagnosis [45]. These medical processes are referred to as clinical pathways. Medical treatment, which is currently based on a combination of intuition, knowledge, and experience of the physician, is being increasingly replaced by structured treatment [48]. Using predefined clinical pathways supports better quality of treatment. According to Picot et al. [49], value can generally not be created by IT directly. IT will only enable the application of processes and can deliver the value afterwards. A requirement for the successful implementation of IT has to be derived from the strategy and the resulting business model. In medical treatment, the processes are clinical pathways derived from evidence-based medicine and enriched by the medical experience of the physician. The daily routines of a medical practice can have several levels of process orientation. The practice of a general practitioner, for example, is likely to have a less structured environment because of a larger variety of the diseases being treated and the shorter time (7 min) of patient contact [50]. Thus, we assumed:

\section{H9. Process orientation positively influences the PEOU of EHS.}

Table 1 summarizes our nine hypotheses that form the research model in Fig. 3.

\section{Methods}

\subsection{Sample description}

The Bavarian testbed for Telemedicine has 452,000 inhabitants spread out over 2847 square kilometers. The region is geographically well-defined because of its heterogeneous structure, making it suitable for field testing [51]. The sample consisted of primary care providers and medical specialists evenly distributed between the two groups. The medical specialist areas in ambulatory care which are certified to offer specialized treatment and bill for their services are, e.g., dermatologists, surgeons, and radiologists. They need special trainings and certification to open a practice in German ambulatory care. The average practice employs 2.1 physicians and 4.5 assistive personnel. The average age of physicians in the study was 49.7 years and the average number of consultations 


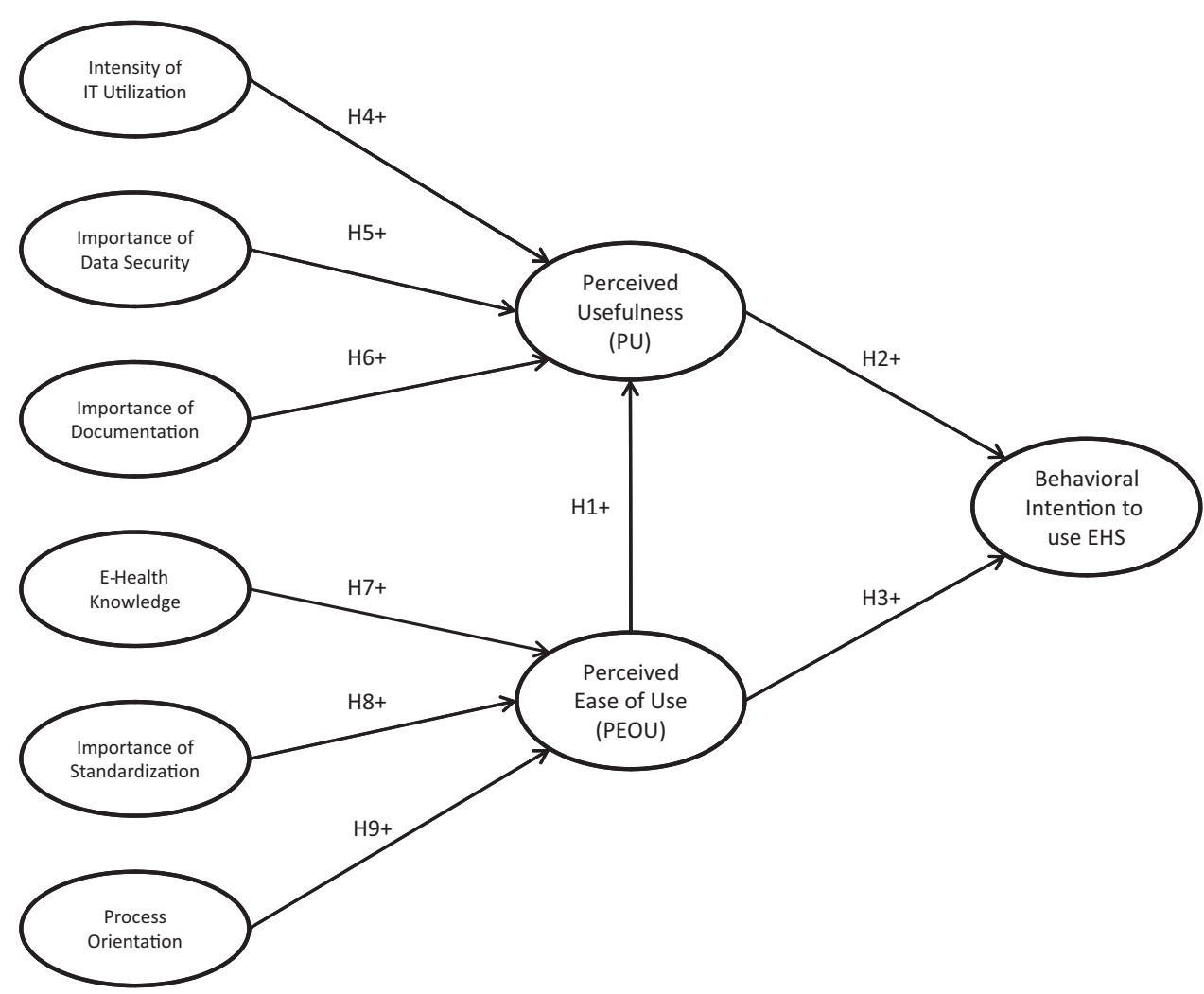

Fig. 3 - Structural Model of Hypothesis.

per day was 46.5 each lasting an average of about $6 \mathrm{~min}$. Approximately 86 patients were seen in each practice per day. The structural data in our research does not significantly differ from the data currently available for the whole of German ambulatory care [52] (Table 2).

\subsection{Survey instrument}

The survey was developed based on the TAM and the UTAUT to determine the intent to use EHS as presented in the NTI. The core of this research is therefore to identify how the characteristics of medical ambulatory practices and the attitude of physicians affect the usage intention of EHS. Based on medical topics, frequently discussed by leading institutions in the healthcare system and the German government
[53-55], we investigated healthcare-related aspects such as: (1) current importance of IT, (2) security requirements of the practice, (3) intensity of documentation, (4) e-health-related knowledge, (5) standardization in the practice, and (6) process orientation of treatment. We reviewed the literature for these topics, developed question items and set up hypothesis on their relation with constructs of technology acceptance. The items were operationalized in a questionnaire for ambulatory physicians. Questions on the characteristics of the healthcare professionals and their practices and attitudes towards their work were raised before questions on telemedicine, ehealth and EHS were addressed in the questionnaire. With this structure we aimed to reduce the self-selection bias for participants with little exposure to IT also in order to measure their general attitude towards the items of our model.

\section{Table 2 - Structural data [57].}

Sample: $N=117$

Germany: $N=137,500$ 
We did not ask for one particular e-health application; rather, we included various applications including e-prescribing, EHR, electronic discharge letters and emergency records. The question sequencing was designed to ensure minimum influence of public opinion on the answer patterns: general concepts, e.g., standardization, were not directly related to telemedicine. The questionnaire was named "Survey on IT diffusion in ambulatory healthcare."

We investigated the state of conventional IT in ambulatory medical practices as well as its use by physicians. The goal was to gain information on the status quo of the testing region concerning the aspects previously mentioned. Further, we were keen to assess the medical domain-related characteristics of medical personnel and practices which are predictable when measuring usage intention based on the TAM model. We picked the items tested in the TAM and UTAUT model for the operationalization of the constructs necessary to determine the behavioral intention to use. These were: (1) PU (as in TAM)/Performance Expectancy (as in UTAUT), (2) Effort Expectancy (UTAUT)/PEOU (TAM) and (3) Usage Intention (UTAUT) Intention to Use the System (TAM). The sex, age, medical specialization and work experience of the participants were included as control variables in the research as we thought these variables would have the strongest effects on our results. However, we applied multi-group analysis but found no differences. In some cases, we did not use exactly the same items to operationalize constructs as used in the original models. We selected other items that were the most suitable in the context of German healthcare and e-health in particular, those taken from the UTAUT construct selection [28]. We preferred items with the highest loading and those with an internal consistency reliability (ICRs) greater than 0.70 .

Initially, we used an explorative research approach to allow for the inclusion of unexpected results [56,57]. We conducted five semi-standardized interviews with physicians in ambulatory care located in the testbed. These results were used to elaborate, operationalize, and transfer the theoretical framework (Table 3) into a structural equation model. To ensure face validity of our self-developed scales, we discussed these with our interview partners as well as subject-matter experts from the domain of e-health. The interview partners also conducted a pre-test of the scales in order to reduce concept ambiguity. Minor changes to the scales were made. Each construct is represented by a set of indicators, which were questions in a questionnaire measured on a five-point Likert scale.

\subsection{Data collection}

We distributed exactly 500 questionnaires by mail to all ambulatory care physicians registered in the Bavarian testbed for telemedicine and provided them access to a web-based questionnaire as well. All ambulatory physicians of the region were targeted in the study, including those without Internet access. Participation in the study was entirely voluntary and no remuneration was provided. One reminder was sent out by fax to all physicians one week after the initial call for participation.

In total, 119 physicians took part in the survey resulting in 117 completed questionnaires, representing a response rate of $23.2 \%$. In these 117 data sets, all 10 blocks of questions were answered completely. Only 4 physicians used the online option to submit their results, the remaining 113 returned it by mail.

\subsection{Data analysis}

The research model was operationalized and transferred into a structural equation model (SEM) to be analyzed with the partial least square (PLS) approach [58,59]. PLS is a method for analyzing causal relationships between multiple variables and is particularly suitable if a more explorative analysis close to the empirical data is preferred. To our knowledge, there is no strong theoretical foundation or empirical evidence of the interplay of determinants and effects on the usage intention of EHS apart from general models on technology acceptance. For these reasons, we believe that an explorative approach was the most appropriate. All calculations for the data analysis were carried out with Smart PLS Version 2.0 [60]. Settings were left to default, except the bootstrap settings. Bootsetting samples were increased to 500 and bootstrapping cases were set to 117 .

As suggested by numerous authors of technology acceptance research, we operationalized the determinants of the formation of behavioral usage intention (i.e., characteristics of the physician, IT utilization intensity) as reflective constructs. The quality of the reflective measurement model is determined by:

- convergent validity indicating that items are statistically associated with the appropriate constructs based on theoretical considerations

- discriminant validity indicating that factors are statistically independent of each other, and

- construct reliability indicating the consistency of our measurement.

\section{Results}

\subsection{Model validation and hypotheses testing}

Before testing our hypotheses, we assessed the reliability and validity of the used reflective constructs and our research model. Tests were conducted to show validity of the model constructs for the overall sample to ensure adequate performance of the measurements.

Convergent validity was tested using the composite reliability (CR), and the average variance extracted (AVE) [61]. Estimated indices were above the recommended thresholds of 0.6 [62] respectively 0.7 [63] for CR and 0.5 for AVE [61]. Discriminant validity of the construct items was assured by looking at the cross loadings which were obtained by correlating the component scores of each latent variable with both their respective block of indicators and all other items included in the model [58]. As depicted in Table 4, all items load higher on their respective construct than on any other construct. Furthermore, the square root of AVE for each construct was higher than correlations between constructs (Table 5) [61]

As this Fornell-Larcker-Criterium was met, discriminant validity for all constructs can be assumed. Table 5 depicts load/weight of items, construct reliability measures and AVE where applicable. Construct reliability is analyzed by 
Table 3 - Mean scores and standard deviations (SD) of each item in the questionnaire related to the research model constructs.

\begin{tabular}{|c|c|c|c|c|}
\hline Construct & Item & Mean & SD & Question/indicator/factor \\
\hline \multirow[t]{4}{*}{$\begin{array}{l}\text { Perceived Importance of } \\
\text { Data Security }\end{array}$} & Sec1 & 1.68 & 1.088 & $\begin{array}{l}\text { National security standards for the handling of patients' medical data are } \\
\text { necessary. }\end{array}$ \\
\hline & Sec2 & 1.81 & 1.079 & $\begin{array}{l}\text { Committing standards for the handling of patients' medical data are necessary } \\
\text { for my practice. }\end{array}$ \\
\hline & Sec3 & 1.96 & 1.013 & $\begin{array}{l}\text { It is important to me to be able to extensively inform my patients about the use } \\
\text { of their medical data. }\end{array}$ \\
\hline & Sec4 & 3.62 & 1.222 & $\begin{array}{l}\text { Abandoning central storage of patients' data will inevitably result in delay of } \\
\text { treatment processes. }\end{array}$ \\
\hline \multirow[t]{4}{*}{$\begin{array}{l}\text { Perceived Intensity of } \\
\text { Documentation }\end{array}$} & Doc1 & 2.60 & 1.083 & $\begin{array}{l}\text { Comprehensive treatment documentation among all participating healthcare } \\
\text { professionals is essential. }\end{array}$ \\
\hline & Doc2 & 2.70 & 1.049 & It is important to provide comprehensive medical documentation. \\
\hline & Doc3 & 2.21 & 0.999 & $\begin{array}{l}\text { Thorough medical documentation contributes crucially to the success of a } \\
\text { therapy. }\end{array}$ \\
\hline & Doc4 & 2.38 & 1.016 & $\begin{array}{l}\text { Standardized documentation eases the exchange of medical information among } \\
\text { healthcare professionals. }\end{array}$ \\
\hline \multirow{4}{*}{$\begin{array}{l}\text { Perceived Intensity of IT } \\
\text { Utilization }\end{array}$} & IT1 & 2.23 & 1.106 & IT Systems provide added value to our practice. \\
\hline & IT2 & 1.90 & 1.083 & Our practice could not be managed efficiently without IT. \\
\hline & IT3 & 2.13 & 1.060 & $\begin{array}{l}\text { Electronic communication will be common in the public health system within } \\
\text { the coming } 5 \text { years. }\end{array}$ \\
\hline & IT4 & 2.38 & 1.188 & $\begin{array}{l}\text { Standardized communication mechanisms with other healthcare professionals } \\
\text { are important to me. }\end{array}$ \\
\hline \multirow{4}{*}{$\begin{array}{l}\text { Perceived Level of } \\
\text { eHealth related } \\
\text { knowledge }\end{array}$} & Know1 & 3.89 & 1.123 & $\begin{array}{l}\text { I've already made myself familiar with model processes of eHC, which are } \\
\text { relevant to my practice. }\end{array}$ \\
\hline & Know2 & 3.86 & 1.132 & $\begin{array}{l}\text { I've already made myself familiar with the technical infrastructure, which has to } \\
\text { be installed in my practice. }\end{array}$ \\
\hline & Know3 & 4.49 & 0.936 & $\begin{array}{l}\text { I've already visited a model practice to make myself familiar with the } \\
\text { infrastructure and processes. }\end{array}$ \\
\hline & Know4 & 4.01 & 1.088 & $\begin{array}{l}\text { I'm familiar with security standards of patients' medical data, which will be } \\
\text { used with EHS. }\end{array}$ \\
\hline \multirow{4}{*}{$\begin{array}{l}\text { Perceived Importance of } \\
\text { Standardization }\end{array}$} & Stan1 & 2.89 & 1.140 & I am in favor of standardized documentation for medical practices. \\
\hline & Stan2 & 3.36 & 1.173 & $\begin{array}{l}\text { In case of standardized treatment processes, the administrative effort exceeds } \\
\text { the medical benefits. }\end{array}$ \\
\hline & Stan3 & 2.49 & 1.070 & $\begin{array}{l}\text { I am in favor of standardized administrative documentation for medical } \\
\text { practices. }\end{array}$ \\
\hline & Stan4 & 3.15 & 1.077 & $\begin{array}{l}\text { Daily work in medical practices is too heterogeneous to standardize important } \\
\text { processes. }\end{array}$ \\
\hline \multirow[t]{4}{*}{$\begin{array}{l}\text { Perceived Importance of } \\
\text { Process Orientation }\end{array}$} & Proc1 & 2.29 & 1.028 & $\begin{array}{l}\text { Our practice maintains structured contact with other medical practices during } \\
\text { inter-institutional treatments. }\end{array}$ \\
\hline & Proc2 & 1.75 & 0.756 & Treatment processes of our practice are documented. \\
\hline & Proc3 & 2.72 & 1.163 & Practice processes are aligned to the IT Systems we are using. \\
\hline & Proc4 & 2.93 & 1.361 & A cost-benefit analysis for the processes within practice would be helpful. \\
\hline \multirow[t]{4}{*}{$\begin{array}{l}\text { Perceived Usefulness } \\
\quad(\mathrm{PU})\end{array}$} & PU1 & 3.29 & 1.276 & $\begin{array}{l}\text { With offers of the health telematics like electronic health record or e-doctor's } \\
\text { letter, I see new potential benefits for my practice. }\end{array}$ \\
\hline & PU2 & 3.32 & 1.227 & The use of health telematics performances will support me in my daily work. \\
\hline & PU3 & 3.52 & 1.214 & $\begin{array}{l}\text { The use of health telematics performances will make it possible to work more } \\
\text { efficiently. }\end{array}$ \\
\hline & PU4 & 3.54 & 1.213 & The use of EHS increases the quality of medical treatment in my practice. \\
\hline \multirow[t]{4}{*}{$\begin{array}{l}\text { Perceived Ease of Use } \\
\quad(\text { PEOU) }\end{array}$} & PEOU1 & 3.24 & 1.278 & $\begin{array}{l}\text { The practice of health telematics performances like electronic health record or } \\
\text { e-doctor's letter would be easy to use. }\end{array}$ \\
\hline & PEOU2 & 2.89 & 1.203 & The handling of health telematics with IT systems would be easy for me to learn. \\
\hline & PEOU3 & 3.55 & 1.147 & E-health systems would be flexible enough to be used in my daily work. \\
\hline & PEOU4 & 3.32 & 1.222 & To learn the handling of e-health systems would take too much time. \\
\hline \multirow{3}{*}{$\begin{array}{l}\text { Behavioral Intention (BI) } \\
\text { to use EHS }\end{array}$} & BI1 & 2.99 & 1.539 & I'd like to use available offers of e-health. \\
\hline & BI2 & 3.17 & 1.529 & I plan to use available offers of e-health. \\
\hline & BI3 & 3.00 & 1.097 & I expect that I have to use the offers of e-health. \\
\hline
\end{tabular}


Table 4 - Cross loadings of the constructs.

\begin{tabular}{|c|c|c|c|c|c|c|c|c|c|}
\hline & DOC & PEOU & IT & KNOW & $P E$ & PROC & SEC & STAN & BI \\
\hline DOC 1 & 0.8053 & 0.4481 & 0.676 & 0.069 & 0.5829 & 0.47 & 0.4341 & 0.5351 & 0.5243 \\
\hline DOC 2 & 0.751 & 0.3611 & 0.313 & 0.0753 & 0.4373 & 0.3106 & 0.3782 & 0.3509 & 0.4159 \\
\hline DOC 3 & 0.7255 & 0.2724 & 0.3376 & 0.1904 & 0.3994 & 0.3559 & 0.2813 & 0.4705 & 0.3955 \\
\hline DOC 4 & 0.8276 & 0.3388 & 0.4667 & 0.1127 & 0.469 & 0.3015 & 0.4135 & 0.72 & 0.3508 \\
\hline PEOU 1 & 0.2988 & 0.8813 & 0.4241 & 0.2362 & 0.6427 & 0.3599 & 0.1671 & 0.3352 & 0.5568 \\
\hline PEOU 2 & 0.2385 & 0.837 & 0.2196 & 0.3103 & 0.4379 & 0.236 & 0.1312 & 0.3114 & 0.4398 \\
\hline PEOU 3 & 0.5923 & 0.8547 & 0.5138 & 0.1353 & 0.7375 & 0.3151 & 0.4534 & 0.5706 & 0.6186 \\
\hline IT 1 & 0.3658 & 0.327 & 0.7698 & 0.0826 & 0.4368 & 0.4104 & 0.111 & 0.3552 & 0.3969 \\
\hline IT 2 & 0.3521 & 0.4206 & 0.8243 & 0.0978 & 0.4432 & 0.4957 & 0.244 & 0.3448 & 0.408 \\
\hline IT 3 & 0.5389 & 0.3731 & 0.7557 & 0.1093 & 0.489 & 0.3661 & 0.2408 & 0.4028 & 0.5053 \\
\hline IT 4 & 0.6154 & 0.3785 & 0.8213 & 0.087 & 0.5096 & 0.4956 & 0.3739 & 0.4856 & 0.463 \\
\hline KNOW 1 & 0.1124 & 0.1578 & 0.1634 & 0.864 & 0.0366 & 0.1742 & 0.0997 & 0.0949 & 0.1765 \\
\hline KNOW 2 & 0.1364 & 0.2868 & 0.0997 & 0.9344 & 0.0894 & 0.2469 & 0.029 & 0.1543 & 0.2219 \\
\hline KNOW 3 & 0.1833 & 0.1953 & 0.1424 & 0.795 & 0.1484 & 0.1483 & 0.1948 & 0.207 & 0.1952 \\
\hline KNOW 4 & 0.0367 & 0.1932 & 0.0232 & 0.874 & -0.0118 & 0.1839 & -0.0294 & 0.0489 & 0.1252 \\
\hline PU 1 & 0.618 & 0.6732 & 0.5744 & 0.0641 & 0.9139 & 0.2719 & 0.4475 & 0.5652 & 0.7046 \\
\hline PU 2 & 0.5963 & 0.7189 & 0.5789 & 0.07 & 0.9607 & 0.3152 & 0.4593 & 0.5494 & 0.6888 \\
\hline PU 3 & 0.5385 & 0.7028 & 0.5517 & 0.0971 & 0.9419 & 0.3118 & 0.386 & 0.5294 & 0.6713 \\
\hline PU 4 & 0.5391 & 0.6157 & 0.5041 & 0.0657 & 0.9032 & 0.2489 & 0.4081 & 0.5461 & 0.6427 \\
\hline PROC 1 & 0.2467 & 0.1432 & 0.2522 & 0.2068 & 0.1567 & 0.4932 & 0.0408 & 0.1056 & 0.0721 \\
\hline PROC 2 & 0.2896 & 0.2159 & 0.2477 & 0.2092 & 0.1288 & 0.6669 & -0.0276 & 0.1968 & 0.1202 \\
\hline PROC 3 & 0.3585 & 0.2814 & 0.5014 & 0.1565 & 0.2509 & 0.7589 & 0.0514 & 0.2448 & 0.1993 \\
\hline PROC 4 & 0.3362 & 0.28 & 0.4174 & 0.0731 & 0.2568 & 0.6971 & 0.2638 & 0.2632 & 0.3171 \\
\hline SEC 1 & 0.3206 & 0.1906 & 0.105 & -0.0429 & 0.2536 & 0.0035 & 0.6938 & 0.3283 & 0.156 \\
\hline SEC 2 & 0.3286 & 0.1858 & 0.0766 & -0.0014 & 0.2307 & 0.0416 & 0.7522 & 0.3058 & 0.1504 \\
\hline SEC 3 & 0.362 & 0.1602 & 0.3132 & 0.0954 & 0.1914 & 0.2869 & 0.5792 & 0.2393 & 0.1515 \\
\hline SEC 4 & 0.3414 & 0.2736 & 0.3059 & 0.1181 & 0.446 & 0.0979 & 0.6968 & 0.3515 & 0.3979 \\
\hline STD 1 & 0.7059 & 0.4136 & 0.4728 & 0.1501 & 0.5089 & 0.3129 & 0.5071 & 0.8472 & 0.4006 \\
\hline STD 2 & 0.335 & 0.3066 & 0.2609 & 0.0464 & 0.4254 & 0.0645 & 0.273 & 0.6124 & 0.2971 \\
\hline STD 3 & 0.494 & 0.3496 & 0.3612 & 0.2189 & 0.3136 & 0.4183 & 0.3186 & 0.7279 & 0.3357 \\
\hline STD 4 & 0.3894 & 0.3635 & 0.3615 & 0.0144 & 0.4699 & 0.12 & 0.2286 & 0.7235 & 0.3148 \\
\hline BI 1 & 0.6019 & 0.6612 & 0.6161 & 0.1962 & 0.7659 & 0.3371 & 0.4062 & 0.5546 & 0.9448 \\
\hline BI 2 & 0.5093 & 0.6079 & 0.5202 & 0.2019 & 0.6875 & 0.2559 & 0.3565 & 0.4249 & 0.9652 \\
\hline BI 3 & 0.2424 & 0.3446 & 0.2512 & 0.1543 & 0.3669 & 0.116 & 0.112 & 0.1165 & 0.6824 \\
\hline
\end{tabular}

individual item reliability [64]. Individual item reliability can be examined by looking at the construct loadings. In the model tested, all loadings were significant at the 0.0001 level and most of them were above the recommended 0.7 parameter value [65]. We removed one item of our Perceived Importance of standardization scale, one item of our Perceived Importance of IT-Security scale and one item of our Perceived Importance of Process Orientation scale that missed this recommendation significantly. As the scales applied in our research model were in part newly developed, this can be considered as very good.

After checking that the measures behave appropriately for the overall data set, the structural model was evaluated. The adequacy of constructs in the structural model allows the evaluation of the explanatory power of the entire model as well as the estimation of the predictive power of the independent variables for both groups. Table 5 depicts the results of the PLS approach.

The explanatory power was examined by looking at $R^{2}$ values of the dependent variables that described the amount of explained variance of the variable. The $R^{2}$ value for the variable PEOU $\left(R^{2}=0.308\right)$ was sufficiently high, explaining the $30.8 \%$ variance of the variable. A total of $67.6 \%\left(R^{2}=0.676\right)$ in the overall sample of the variation of the construct performance expectancy was explained by the three exogenous variables (i.e., Intensity of IT Utilization, Importance of Data Security, Importance of Documentation) and the PEOU, which is very high. Finally, our research model can explain $55.6 \%$ of variation of usage intention $\left(R^{2}=0.556\right)$.

We tested our hypotheses by analyzing the standardized path coefficients between constructs together with the corresponding t-values calculated by the bootstrapping procedure. These path coefficients indicate the relative strength of the influence of the independent variables (e.g., perceived importance of data security) on the dependent variables (e.g., PU). Bootstrapping reveals significance for all path coefficients in the overall model so that all hypotheses are accepted. Fig. 4 depicts the structural model findings. The influences of the knowledge level (H7) and process orientation (H9) on the PU were significant $(p<0.05)$ as was the importance of standardization (H8) $(p<0.01)$. Similarly, the influences of data security importance (H5) and documentation intensity (H6) on the PEOU were significant $(p<0.05)$ and the perceived importance of standardization (H8) was significant $(p<0.01)$. The analysis of the overall effect size $\left(f^{2}\right)$ of the antecedents of PEOU revealed that all constructs had a low effect except for the path coefficient of Perceived Intensity of Standardization that had a moderate effect meaning that this variable has a stronger effect on PEOU than the other two variables. In regard to PU all items have a low effect size.

The effect size for the path coefficient between PU and BI was high whereas the effect size between PEOU and BI was low. Finally, the Stone-Geißer- $\mathrm{Q}^{2}$, a measure indicating the overall 


\begin{tabular}{|c|c|c|c|c|c|}
\hline Construct & Item & Load/weight & Significance level & CR & AVE \\
\hline \multirow[t]{4}{*}{ Perceived Importance of Data Security } & Sec1 & 0.694 & 0.0001 & \multirow{4}{*}{0.7670} & \multirow{4}{*}{0.5237} \\
\hline & $\operatorname{Sec} 2$ & 0.758 & 0.0001 & & \\
\hline & (Sec 3 & 0.579 & $0.0001)$ & & \\
\hline & $\operatorname{Sec} 4$ & 0.697 & 0.0001 & & \\
\hline \multirow[t]{4}{*}{ Perceived Intensity of Documentation } & Doc1 & 0.805 & 0.0001 & \multirow{4}{*}{0.8598} & \multirow{4}{*}{0.6059} \\
\hline & Doc2 & 0.751 & 0.0001 & & \\
\hline & Doc3 & 0.725 & 0.0001 & & \\
\hline & Doc4 & 0.828 & 0.0001 & & \\
\hline \multirow[t]{4}{*}{ Perceived Intensity of IT Utilization } & IT1 & 0.770 & 0.0001 & \multirow{4}{*}{0.8715} & \multirow{4}{*}{0.6294} \\
\hline & IT2 & 0.824 & 0.0001 & & \\
\hline & IT3 & 0.756 & 0.0001 & & \\
\hline & IT4 & 0.821 & 0.0001 & & \\
\hline \multirow[t]{4}{*}{ Perceived Level of e-health related knowledge } & Know1 & 0.864 & 0.0001 & \multirow{4}{*}{0.9243} & \multirow{4}{*}{0.7539} \\
\hline & Know2 & 0.934 & 0.0001 & & \\
\hline & Know3 & 0.795 & 0.0001 & & \\
\hline & Know4 & 0.874 & 0.0001 & & \\
\hline \multirow[t]{4}{*}{ Perceived Importance of Standardization } & Stan1 & 0.847 & 0.0001 & \multirow{4}{*}{0.8205} & \multirow{4}{*}{0.5235} \\
\hline & Stan2 & 0.612 & 0.0001 & & \\
\hline & Stan3 & 0.728 & 0.0001 & & \\
\hline & Stan4 & 0.724 & 0.0001 & & \\
\hline \multirow[t]{4}{*}{ Perceived Importance of Process Orientation } & (Process 1 & 0.493 & $0.0001)$ & \multirow{4}{*}{0.7686} & \multirow{4}{*}{0.5237} \\
\hline & Process 2 & 0.667 & 0.0001 & & \\
\hline & Process 3 & 0.759 & 0.0001 & & \\
\hline & Process 4 & 0.69 & 0.0001 & & \\
\hline \multirow[t]{4}{*}{ Perceived Usefulness } & PU1 & 0.916 & 0.0001 & \multirow{4}{*}{0.9625} & \multirow{4}{*}{0.8652} \\
\hline & PU2 & 0.961 & 0.0001 & & \\
\hline & PU3 & 0.940 & 0.0001 & & \\
\hline & PU4 & 0.902 & 0.0001 & & \\
\hline \multirow[t]{3}{*}{ Perceived Ease of Use } & PEOU1 & 0.879 & 0.0001 & \multirow{3}{*}{0.8934} & \multirow{3}{*}{0.7365} \\
\hline & PEOU 2 & 0.841 & 0.0001 & & \\
\hline & PEOU 3 & 0.854 & 0.0001 & & \\
\hline \multirow[t]{3}{*}{ Behavioral Intention to use EHS } & BI1 & 0.945 & 0.0001 & \multirow{3}{*}{0.9044} & \multirow{3}{*}{0.7633} \\
\hline & BI2 & 0.965 & 0.0001 & & \\
\hline & BI3 & 0.682 & 0.0001 & & \\
\hline
\end{tabular}

$\mathrm{CR}$, composite reliability; AVE, average variance extracted; Values in parentheses were not included into analysis.

fit of the proposed model, for our main endogenous variables (performance expectancy, PEOU and usage intention) was $>0$. Thus, a sufficient predictive validity of our research model can be assumed. These findings support our theoretical model at a general level using the overall data set.

\section{Discussion}

The research model we describe explains the difficult situation of the German NTI and the partially low usage intention of e-health applications in Germany. In accordance with previously conducted quantitative TAM studies $[15,16]$, our results showed that PU and PEOU are highly significant for the usage intention for EHS in German ambulatory care. Hence, our findings confirm those from major TAM research in e-health. In addition to the verification of the TAM model for e-health in German ambulatory care, the drivers and burdens included in our model were used to explain the constructs PU and PEOU. All items in the developed model have significant influence on these items. In ambulatory medical practices with little standardization, process orientation, and e-health knowledge, the adoption of e-health is regarded as a major effort. These are most likely to be small practices (general practitioners). The PU was high for those physicians who have high security demands, thus requiring comprehensive documentation because of the heavy utilization of IT. Privacy concerns were not a key barrier for the acceptance of e-health among health professionals in Germany. Physicians with high security demands had higher usage intentions for EHS compared to physicians with lower security demands. Hence, EHS can be considered a significant enabler for secure data processing in healthcare [66].

Heavy demands for documentation lead to higher performance expectations of e-health applications. As comprehensive documentation requires connected IS, traditional documentation seems to be unsuitable for this purpose. The current utilization of IT in medical practices seems to be a driver for usage intention of e-health. It seems the higher the current IT demand, the better the performance expectation of e-health. Physicians with low demand for IT in general, those who do not have much variation in daily routines, did not 


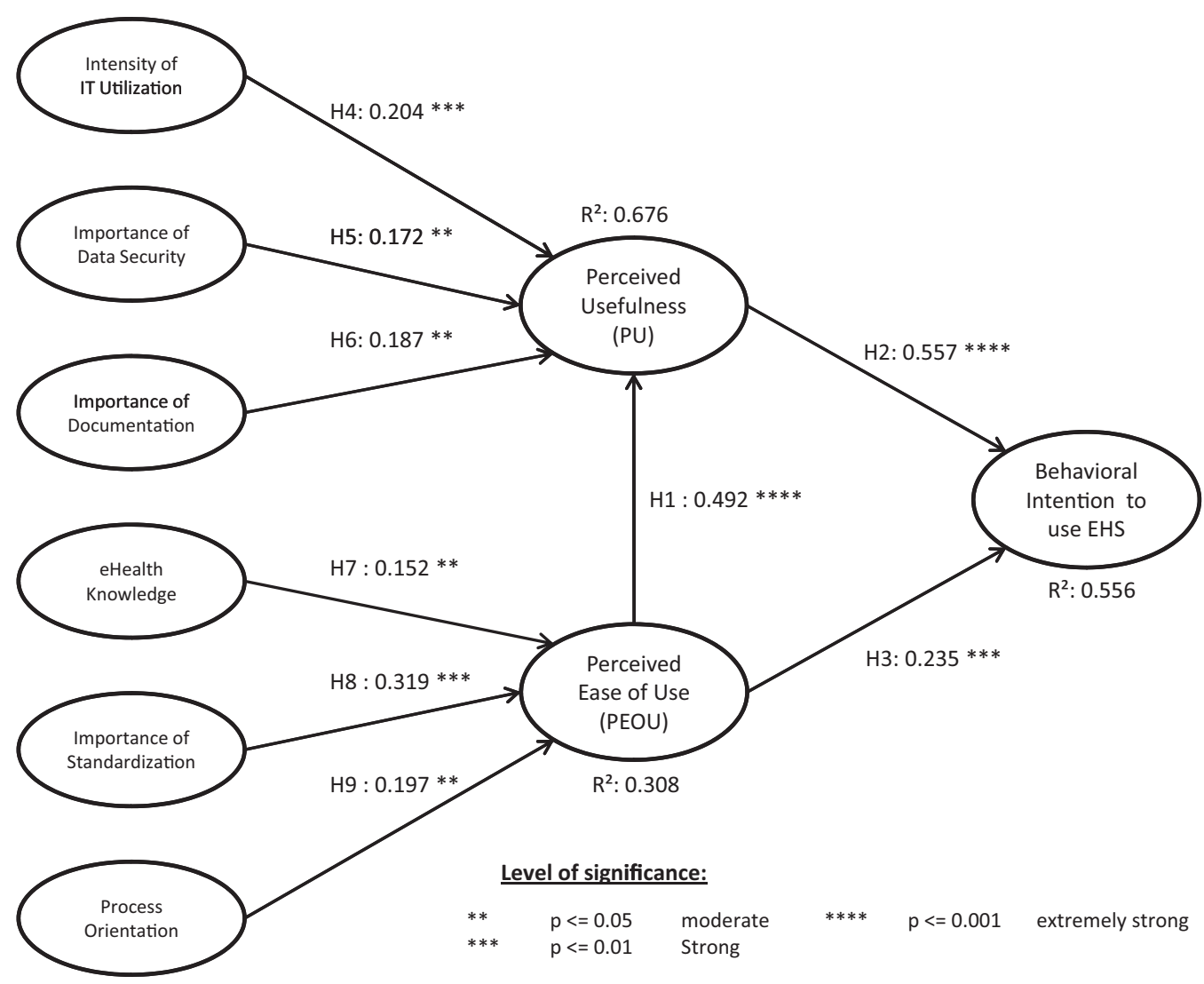

Fig. 4 - Usage Intention Model for EHS - Structural Model.

regard EHS as an important technology. For these physicians, e-health offers few advantages for their work.

Previous research on physician use of EHS has shown that general practitioners show significantly lower usage intention than do medical specialists. Previous research has also shown that the number of daily treatments has an effect on the rate of adoption of EHS. In the US, small medical practices have significantly lower adoption of advanced EHR than larger medical facilities or institutions. The reason for this difference is likely not just the size of the practice, but also the state of process orientation, standardization, documentation, and internal systematization existing in small practice. Thus, our research underlines the importance of standardizations and process orientation in healthcare to reduce the initial barriers for using EHS.

Process definition and standardization prior to the implementation of advanced IT systems is a long-established practice in the application of IS; IT is only a tool to enable new business processes [67]. Efforts to establish standards and mandatory treatment processes must be pushed forward if the adoption of e-health is an overall goal as it was one of our major influence factors in the model. Many physicians already comply with evidence-based treatment guidelines; a small percentage of physicians, however, have not integrated these guidelines into practice. Further, it appears that when IT-related knowledge is high, there is lower perceived effort to use e-health. Comprehensive training and information campaigns about the potential and the function of IT might have positive impact on the future adoption of e-health.
Many TAM studies in the past limited their research of technology acceptance to either a specific group of physicians or a single e-health technology, or to EHR [68] or handheld computers [69]. Our research targeted a broader spectrum of technologies and considered various groups of physicians. The decision to adopt technology by ambulatory care physicians in private practice is voluntary and made by one or few people whereas the implementation of IS projects in larger facilities and institutions is often non-voluntary, made by many people, and can fail due to the resistance of groups of key-stakeholders. Acceptance work for the German NTI must reduce barriers for e-health adoption and support the drivers accordingly. Incentives must be established for the adoption of enhanced documentation, treatment, as well as security standards and well-defined administrative and medical processes. In general, the installation of IS and e-health knowledge should be strengthened. Our proposed research model could reduce the perceived effort related to using ehealth and enhance the performance expectancy of e-health.

\subsection{Contribution to theory}

TAM research is a wide field, especially in IS. Various articles have verified the validity of established TAM constructs, explaining the acceptance of a software system. However, the impact factors determining the PEOU and the PU, constructs that have shown extreme influence on the usage intention, have not been addressed in previous research. We investigated the perceived importance of e-health related characteristics 
and their influence on using or rejecting EHS in a wide spectrum of ambulatory care practices. Our extension of the TAM model explains how variations in usage intention are influenced by e-health perception in physicians practicing in an ambulatory care setting. The acceptance theory which evolved from our research could be refined for application in larger facilities and institutions considering the adoption of EHS.

\subsection{Limitations and further research}

Due to the diversity of healthcare, especially in ambulatory settings, a universal technology acceptance model for e-health is hardly feasible. There is large diversity in public health systems around the world. These diversities must be integrated into TAM research to properly explain the drivers and burdens in TAM research. This research could only validate the extension of the TAM model within a limited setting. It only includes a limited set of 117 ambulatory care physicians in a specific region of southern Germany. The mindset of these physicians can be influenced by the specific aspects of the German public health system as well as by regional characteristics. German ambulatory care physicians, e.g., work mostly independent, while many public health systems around the world attach ambulatory care to hospitals or medical centers. Nationwide and even international studies should be conducted to validate the hypothesis of the paper in a broader context. Some shortcomings were found in the TAM model, inclusion of new variables grounded in emotional, group, social or cultural behavior can improve the results based on the national environment [70]. Research should furthermore target sophisticated technology acceptance campaigns in order to best consider individual characteristics of physicians to enhance the adoption of e-health.

\section{Author contributions}

Sebastian Dünnebeil designed the study. Ali Sunyaev, Jan Marco Leimeister, Ivo Blohm and Helmut Krcmar contributed to the design of the study by review and adaption of the underlying research model.

\section{Conflict of interest}

All authors disclose any financial and personal relationships with other people or organizations that inappropriately influence (bias) this work. None of the authors has other employments than listed in the affiliations. No payments where received in relation to this work due to consultancies, stock ownership, honoraria, paid expert testimony or patent applications.

\section{Acknowledgements}

The study was conducted in the context of the research project "Use and Security of the German electronic Health Card System (eHC) in Bavaria". It is a research project of the Technische Universität München funded by the Bavarian Ministry of Environment and Health. The study was not influenced, designed

\section{Summary points}

What was already known before the initiation of the study?

- The applicability of established technology acceptance models, TAM and UTAUT, in the healthcare environment.

- The constructs, perceived ease of use and perceived usefulness, have a high influence on the usage intention for various e-health technologies.

- Existing literature on the application of TAM and UTAUT in healthcare.

What has the study added to the body of knowledge?

- The validity of the TAM constructs, as tested in the environment of German ambulatory healthcare, is supported by evidence from previous studies.

- Various characteristics of medical ambulatory care practices significantly influence the important TAM constructs perceived usefulness (PU) and perceived ease of use (PEOU).

- Identified characteristics of medical ambulatory care practices with high interest in e-health or strong objection to health.

or reviewed by the founding source in any way. The authors thank Carol Krcmar for critical review and editing of this paper.

REFERENCES

[1] European Commission, eHealth for Safety Report, Office for Official Publications of the European Communities, Luxembourg, 2007.

[2] P. Shekelle, S.C. Morton, E.B. Keeler, Costs and Benefits of Health Information Technology, 2006.

[3] P. Whitten, C. Steinfield, S. Hellmich, eHealth: market potential and business strategies, Journal of Computer-Mediated Communication 6 (4) (2001).

[4] J.M. Lappé, J.B. Muhlestein, D.L. Lappé, R.S. Badger, T.L. Bair, R. Brockman, T.K. French, L.C. Hofmann, B.D. Horne, S. Kralick-Goldberg, N. Nicponski, J.A. Orton, R.R. Pearson, D.G. Renlund, H. Rimmasch, C. Roberts, J.L. Anderson, Improvements in 1-year cardiovascular clinical outcomes associated with a hospital-based discharge medication program, Annals of Internal Medicine 141 (6) (2004) 446-453.

[5] T. Helms, J. Pelleter, D. Ronneberger, Telemedical care of chronic heart failure, examples of the training- and care program "Telemedicine for the heart", Herz 32 (8) (2007) 623-629 (in German).

[6] K. Kempf, C. Schulz, Telemedicine for Diabetes: Higher Therapy Satisfaction, Improved Vital Parameters, 2008 (in German).

[7] German Ministry of Health, The German eHealth Strategy (Target and Strategy, Concept, Legal Framework, Activities/Roll-out Plan, Costs and Return of Investment, European Perspective), German Ministry of Health, Berlin/Bonn, 2005. 
[8] Allensbach Institute, Application of Telematics in the Public Health System - Results of a Representative Study Among Physicians in Ambulatory Care and Hospitals, Allensbach am Bodensee, 2010 (in German).

[9] A. Tuffs, Germany plans to introduce electronic Health Card, BMJ 329 (7458) (2008) 131-140.

[10] C. DesRoches, E. Campbell, S. Rao, K. Donelan, T. Ferris, A. Jha, R. Kaushal, D. Levy, S. Rosenbaum, A. Shields, D. Blumenthal, Electronic Health records in ambulatory care-a national survey of physicians, The New England Journal of Medicine 359 (1) (2008) 50.

[11] C.M. Angst, R. Agarwal, Adoption of electronic health records in the presence of privacy concerns: the elaboration likelihood model and individual persuasion, Management Information Systems Quarterly 33 (2) (2008) 339-370.

[12] Federal Republic of Germany, Code of Social Law (SGB) Fifth Book, Public Health Insurance, 1988 (in German).

[13] Techniker Krankenkasse, Industry Overview - e-Health, vol. 1, FAZ - Institut for Management, Market- and Media, 2009 (in German).

[14] O. Kalthoff, N. Marsden, S. Kalthoff, F. Drescher, Final Report - Evaluation of the Introduction of the electronic Health Card in the Heilbronn Testbed, 2008 (in German).

[15] R.J. Holden, B.-T. Karsh, The technology acceptance model: its past and its future in health care, Journal of Biomedical Informatics 43 (1) (2010) 159-172.

[16] A.K. Yarbrough, T.B. Smith, Technology acceptance among physicians: a new take on TAM, Medical Care Research and Review: MCRR 64 (6) (2007) 650-672.

[17] H. Oh, C. Rizo, M. Enkin, A. Jadad, J. Powell, C. Pagliari, What is eHealth (3): a systematic review of published definitions, Journal of Medical Internet Research 7 (1) (2005).

[18] G. Eysenbach, What is e-health? Journal of Medical Internet Research 3 (2) (2001) e20-e30.

[19] Fraunhofer Institut, Specification of a Solution Architecture to Implement Applications of the electronic Health Card, Fraunhofer, Project Group R\&D-Project, Berlin, 2005 (in German).

[20] M. Marschollek, E. Demirbilek, Providing longitudinal health care information with the new German Health Card - a pilot system to track patient pathways, Computer Methods and Programs in Biomedicine 81 (2006) 266-271.

[21] gematik, Introduction of the electronic Health Card - Overall Architecture, gematik GmbH, 2008 (in German).

[22] R. Bernnat, Costs and Benefits of a Telematics Infrastructure for the German Public Health System, Booz Allen Hamilton $\mathrm{GmbH}, 2006$ (accessed 14.01.2011) (in German) http://www.gkv.info/gkv/fileadmin/user_upload/Projekte/ Telematik_im_Gesundheitswesen/KNA_Endbericht.pdf.

[23] S. Dünnebeil, A. Sunyaev, I. Blohm, J. Leimeister, H. Krcmar, Do German physicians want electronic Health Services? A characterization of potential adopters and rejectors in German Ambulatory Care, in: Third International Conference on Health Informatics (HealthInf 2010), Valencia, 2010.

[24] A. Tuffs, Germany puts universal health e-card on hold, BMJ 340 (1) (2010, January) c171.

[25] F. Davis, User acceptance of information technology: system characteristics, user perceptions and behavioral impacts, International Journal of Man-Machine Studies 38 (3) (1993) 475-487.

[26] P.J. Hu, P.Y.K. Chau, O.R.L. Sheng, K.Y. Tam, Examining the technology acceptance model using physician acceptance of telemedicine technology, Journal of Management Information Systems 16 (2) (1999) 91-112.

[27] Q. Ma, L. Liu, The technology acceptance model: a meta-analysis of empirical findings, Journal of Organizational and End User Computing 16 (1) (2004) 59-72.
[28] V. Venkatesh, M. Morris, G. Davis, F. Davis, User acceptance of information technology: toward a unified view, Management Information Systems Quarterly 27 (3) (2003) 425-478.

[29] S. Pannarunothai, S.M. Speedie, B. Kijsanayotin, Factors influencing health information technology adoption in Thailand's community health centers: applying the UTAUT model, International Journal of Medical Informatics 78 (6) (2009) 404-416.

[30] V. Venkatesh, F.D. Davis, A theoretical extension of the technology acceptance model: four longitudinal field studies, Management Science 46 (2) (2000) 186-204.

[31] I. Ajzen, The theory of planned behavior, Organizational Behavior and Human Decision Processes 50 (2) (1991) 179-211.

[32] T.D. Sequist, T. Cullen, H. Hays, M.M. Taualii, S.R. Simon, D.W. Bates, Implementation and use of an electronic health record within the Indian health service, Journal of the American Medical Informatics Association: JAMIA 14 (2) (2007) 191-197.

[33] J.A. Mitchell, Basic principles of information technology organization in health care institutions, Journal of the American Medical Informatics Association 4 (2) (1997) s31-s35.

[34] R. Gururajan, Drivers for wireless technology acceptance in Indian healthcare, International Journal of Healthcare Delivery Reform Initiatives (1) (2009) 48-62.

[35] D. Boddy, G. King, J. Clark, D. Heaney, F. Mair, The influence of context and process when implementing e-health, BMC Medical Informatics and Decision Making 9 (1) (2009) 9.

[36] K.J. Leonard, D.F. Sittig, Improving information technology adoption and implementation through the identification of appropriate benefits: creating IMPROVE-IT, Journal of Medical Internet Research 9 (2) (2007).

[37] S.S. Lyons, T. Tripp-Reimer, B.A. Sorofman, J.E. DeWitt, B.J. BootsMiller, T.E. Vaughn, B.N. Doebbeling, Information technology for clinical guideline implementation: perceptions of multidisciplinary stakeholders, Journal of the American Medical Informatics Association 12 (1) (2005) 64-71.

[38] W.A. Yasnoff, J.M. Overhage, B.L. Humphreys, M. LaVenture, A national agenda for public health informatics, Journal of the American Medical Informatics Association 8 (6) (2001) 535-545.

[39] Strategies for development and adoption of EHR in German ambulatory care, in: S. Dünnebeil, A. Sunyaev, J.M. Leimeister, H. Krcmar (Eds.), 4th International Conference on Pervasive Computing Technologies for Healthcare (PervasiveHealth), IEEE, Munich, 2010.

[40] V. Venkatesh, Determinants of perceived ease of use: integrating control, intrinsic motivation, and emotion into the technology acceptance model, Information Systems Research 11 (4) (2000) 342-365.

[41] G.J.E.D. Moor, C. McDonald, J.Nv. Goor, Progress in Standardization in Health Care Informatics, IOS Press, 1993.

[42] R.A. Stegwee, T.A.M. Spil, Strategies for Healthcare Information Systems, Idea Group Inc (IGI), 2001.

[43] C. Ohmann, W. Kuchinke, Future developments of medical informatics from the viewpoint of networked clinical research. Interoperability and integration, Methods of Information in Medicine 48 (1) (2009) 45-54.

[44] J. Ingenerf, J. Reiner, B. Seik, Standardized terminological services enabling semantic interoperability between distributed and heterogeneous systems, International Journal of Medical Informatics 64 (2-3) (2001) 223-240.

[45] German Medical Center For Quality Control, National Treatment Guideline for Chronic Heart Failure, Bundesärztekammer, Kassenärztliche Bundesvereinigung, 
Arbeitsgemeinschaft der Wissenschaftlichen Medizinischen Fachgesellschaften, Berlin, 2009 (in German).

[46] K. Shuval, A. Shachak, S. Linn, M. Brezis, P. Feder-Bubis, S. Reis, The impact of an evidence-based medicine educational intervention on primary care physicians: a qualitative study, Journal of General Internal Medicine 22 (3) (2007) 327-331.

[47] R. Lenz, M. Reichert, IT support for healthcare processes premises, challenges, perspectives, Data \& Knowledge Engineering 61 (1) (2007) 39-58.

[48] B. Häussler, Structured treatment of patients with diabetes, Der Diabetologe 2 (6) (2006) 509-516 (in German).

[49] A. Picot, R. Reichwald, R. Wigand, Information, Organization and Management, Springer, 2008.

[50] T. Kurt, Great Britain: physicians - disappointed and disillusioned, Deutsches Ärzteblatt 98 (33) (2001) (in German).

[51] ZTG, German Testbeds for Telemedicine, 2009 (accessed 21.12.2011) (in German) http://www.telematik-modellregionen.de.

[52] KBV, Basic Data of Medical Care in Germany, Association of Statutory Health Insurance Physicians, Berlin, 2008 (in German).

[53] Bundesministerium für Gesundheit, The German eHealth Strategy (Target and Strategy, Concept, Legal Framework, Activities/Roll-out Plan, Costs and Return of Investment, European Perspective), Bundesministerium für Gesundheit, Berlin/Bonn, 2005.

[54] J.-D. Hoppe, M. Richter-Reichhelm, Wrong Medical Treatment in Germany, Central Institute for Medical Quality Control of the German Medical Association and the Association of Statutory Health Insurance Physicians, 2000 (in German).

[55] R. Haux, Health information systems - past, present, future, International Journal of Medical Informatics 75 (3-4) (2005) 268-281.

[56] J. Bortz, N. Döring, Research Methods and Evaluation for Human and Social Science, Springer, Berlin, 2002 (in German).

[57] M.D. Myers, Qualitative Research in Information Systems, Management Information Systems Quarterly 21 (2) (1997) 241-242.
[58] W.W. Chin, The partial least squares approach to structural equation modeling, in: G.A. Marcoulides (Ed.), Modern Methods for Business Research, Lawrence Erlbaum Associates, Mahwah, NJ, 1998, pp. 295-336.

[59] H. Wold, in: S. Kotz, N.L. Johnson (Eds.), Partial Least Squares, Wiley, New York, 1985.

[60] C. Ringgle, S. Wende, J. Becker, SmartPLS, 2005 (accessed 21.12.2011) http://www.smartpls.de.

[61] C. Fornell, D.F. Larcker, Evaluating structural equation models with unobservable variables and measurement error, Journal of Marketing Research 18 (2) (1981) 39-50.

[62] R.P. Bagozzi, Y. Yi, On the evaluation of structural equation models, Journal of the Academy of Marketing Sciences 16 (1) (1988) 74-94.

[63] J.C. Nunnally, Psychometric Theory, 1st ed., McGraw-Hill, New York, 1978.

[64] J. Peter, Reliability: a review of psychometric basics and recent marketing practices, Journal of Marketing Research 16 (February) (1981) 6-17.

[65] E.G. Carmines, R.A. Zeller, Reliability and Validity Assessment, 1st ed., Sage, Beverly Hills, 1979.

[66] A. Kaletsch, A. Sunyaev, Privacy engineering: personal health records in cloud computing environments, in: ICIS 2011 Proceedings. Paper 2, 2011, http://aisel.aisnet.org/icis2011/proceedings/ISsecurity/2.

[67] H. Krcmar, Information Management, 5th ed., Springer, Heidelberg, 2010 (in German).

[68] M.-P. Gagnon, G. Godin, C. Gagné, J.-P. Fortin, L. Lamothe, D. Reinharz, A. Cloutier, An adaptation of the theory of interpersonal behaviour to the study of telemedicine adoption by physicians, International Journal of Medical Informatics 71 (2-3) (2003) 103-115.

[69] M.Y. Yi, J.D. Jackson, J.S. Park, J.C. Probst, Understanding information technology acceptance by individual professionals: toward an integrative view, Information \& Management 43 (3) (2006) 350-363.

[70] R.P. Bagozzi, The legacy of the technology acceptance model and a proposal for a paradigm shift, Journal of the Association for Information Systems 8 (4) (2007). 